\title{
Formação continuada de professoras alfabetizadoras: relações com a alfabetização e letramento
}

\author{
Continuing training of literacy teachers: relationships with literacy \\ and lettering
}

\section{Formación continua de maestros de alfabetización: relaciones con la alfabetización y letramiento}

\section{Leticia Arruda'}

Secretaria Municipal da Educação de Lages, Servidora pública. https://orcid.org/0000-0003-1117-9176

\section{Maria Selma Grosch}

Universidade do Planalto Catarinense, Programa de Pós-graduação em Educação, Professora titular. https://orcid.org/0000-0001-5874-2072

Resumo: A formação continuada é um processo constante, sendo importante que promova a autonomia e a criticidade das professoras alfabetizadoras, além de oportunizar a busca de instrumentos necessários no processo de alfabetização e letramento dos estudantes. Ler e escrever proporcionam aos seres humanos a capacidade de ação segundo suas normas e conceitos e geram as condições necessárias para alcançar níveis mais elevados de aprendizagem. A pesquisa teve como objetivo geral analisar a concepção das professoras alfabetizadoras sobre a alfabetização na perspectiva do letramento. Com abordagem qualitativa, os dados foram coletados por meio de questionário, contendo nove perguntas fechadas, junto a 30 professoras efetivas com experiência em turmas de $1^{\circ}$ e/ou $2^{\circ}$ ano da rede municipal de educação de Lages, SC. Na segunda etapa da pesquisa empírica, foram selecionadas as professoras, de acordo com os critérios de inclusão, para a realização da entrevista semiestruturada. Após a pesquisa, foi possível verificar, de acordo com a percepção das professoras, que as turmas de $1^{\circ}$ e $2^{\circ}$ anos necessitam de um enfoque diferenciado, levando em consideração a importância da alfabetização e do letramento para os estudantes. Exaltam, também, a premência de práticas alfabetizadoras que promovam, com os estudantes, possibilidades de avanços no

Mestre em Educação pela Universidade do Planalto Catarinense; Especialista em Gestão e Práticas Psicopedagógicas pelo Centro Universitário Unifacvest.

2 Pós-doutora em Educação pela Universidade do Oeste de Santa Catarina; Doutora em Educação pela Universidade Federal de Santa Catarina. 
conhecimento e transformação da realidade social em que vivem. Desse modo, torna-se imprescindível que a formação continuada de alfabetizadoras oportunize às professoras aprofundarem questões inerentes a esse processo e que levem em consideração as práticas e exigências educacionais no desenvolvimento dos conteúdos curriculares da Educação Básica.

Palavras-chave: Formação continuada. Alfabetização e letramento. Professoras alfabetizadoras.

Abstract: Continuing education, theme of this dissertation, is a constant process, and it is important that it promotes autonomy and criticality of literacy teachers, in addition to providing the opportunity to search for necessary instruments in the process of students' literacy. Reading and writing promote on human beings the capacity to act according to their norms and concepts and generate the necessary conditions to achieve higher levels of learning. The general objective of the research was to analyze the conception of literacy teachers about alphabetization from the perspective of literacy. With a qualitative approach, the data were collected through a nine closed questions questionnaire, with thirty career teachers with experience in 1st and/or 2nd grade classes of the municipal school system from Lages, SC. In the second stage of the empirical research, the teachers were selected according to the inclusion criteria for the semi-structured interview. After the research, it was possible to verify, according to the teachers' perception, that the 1st and 2nd grade classes need a differentiated approach, taking into account the importance of literacy for the students. They emphasize the urgency of literacy practices that promote, with students, possibilities for advances in knowledge and transformation of the social reality in which they live. Thus, it is essential that the continuing education of literacy teachers gives them the opportunity to deepen the issues inherent in this process and to take into account practices and educational requirements in the development of the curriculum contents of Basic Education.

Keywords: Continuing Education. Literacy. Literacy teachers.

Resumen: La formación continua es un proceso constante, y es importante que promueva la autonomía y la crítica de los maestros de alfabetización, además de brindar oportunidades para buscar los instrumentos necesarios en el proceso de alfabetización y letramiento de los estudiantes. La lectura y la escritura proporcionan a los seres humanos la capacidad de actuar de acuerdo con sus normas y conceptos y generar las condiciones necesarias para alcanzar niveles más altos de aprendizaje. El objetivo general de la investigación fue analizar la concepción de los maestros de alfabetización sobre alfabetización en la perspectiva de letramiento. Con enfoque cualitativo, se recogieron los datos a través de la aplicación de una encuesta con treinta docentes titulares con experiencia en clases de primer y/o segundo año de educación municipal de Lages, SC. En la segunda etapa de la investigación empírica, se seleccionaron diez docentes, según los criterios de inclusión, para la entrevista semiestructurada. Tras la investigación, se pudo verificar, de acuerdo con la percepción de los docentes, que las clases de primer y segundo año necesitan un enfoque diferenciado, teniendo en cuenta la importancia de la alfabetización y letramiento para los estudiantes. También exaltan la urgencia de las prácticas de alfabetización que promueven, con los estudiantes, las posibilidades de avances en el conocimiento y la transformación de la realidad social em que viven. Así que, es esencial 
que la educación continua de los docentes de alfabetización les brinde la oportunidad de profundizar los problemas inherentes a este proceso y que considere las prácticas y requisitos educativos en el desarrollo de los contenidos curriculares de la Educación Básica.

Palabras clave: Formación Continua. Alfabetización y Letramiento. Maestros de Alfabetización.

Recebido em 22 de abril de 2020

Aceito em 10 de julho de 2020

Publicado em 28 de agosto de 2020

\section{INTRODUÇÃO}

Este artigo integra uma dissertação de mestrado que teve como objetivo analisar a concepção das professoras ${ }^{3}$ alfabetizadoras sobre a alfabetização na perspectiva do letramento, conhecendo de que maneira ocorrem seus processos formativos e como estes influenciam e auxiliam a prática pedagógica. A pesquisa de abordagem qualitativa aconteceu durante os anos de 2018 e 2019, junto a 30 professoras alfabetizadoras de $1^{\circ}$ e/ou $2^{\circ}$ ano do Ensino Fundamental da rede municipal de educação de Lages, SC. Inicialmente aplicamos um questionário com as 30 professoras para a identificação de 10 professoras para a entrevista semiestruturada. Partindo da seguinte pergunta: como as professoras da rede municipal de educação de Lages, SC, entendem o processo de alfabetização e letramento a partir da formação continuada ofertada pela Secretaria Municipal de Educação de Lages (SMEL)?

A alfabetização é um tema recorrente no contexto educacional brasileiro, pois faz parte do dia a dia de todas as escolas com Anos Iniciais do Ensino Fundamental, e uma das diretrizes do Plano Nacional de Educação (PNE) 2014-2024 é a "erradicação do analfabetismo" (BRASIL, 2001), meta essa presente desde a Constituição da República Federativa do Brasil de 1988. Levando em consideração tais encaminhamentos, ocorre a formação das professoras que atuam ou atuarão com as turmas de alfabetização, seguindo essas recomendações, relacionadas à sua prática pedagógica e ao entendimento que têm do processo de alfabetização.

Enfatizando toda a importância da temática da alfabetização e do letramento, faz-se necessária uma abordagem relacionando o processo formativo das professoras para renovação de estratégias e enfrentamentos diários encontrados na profissão, bem como

\footnotetext{
3 Para este trabalho foi utilizada a palavra professora, no gênero feminino, quando se trata de docentes que atuam em turmas de alfabetização, pois todas as participantes da pesquisa fazem parte desse gênero, bem como a maioria das professoras alfabetizadoras da rede municipal de educação de Lages.
} 
o acesso aos estudos de especialistas da área, consolidando aprendizagens. A formação continuada tem um papel importante no auxílio às professoras em sala de aula, embora não seja o único, pois vários aspectos influenciam na atuação do profissional da educação e, de acordo com André (2013, p. 37), "São múltiplos os fatores que não podem ser esquecidos nem desconsiderados no delineamento de políticas para os docentes." A formação continuada pode se constituir em importante espaço de diálogo entre as professoras que estão iniciando sua carreira, tanto na troca de saberes pedagógicos quanto na renovação de práticas daquelas que já têm experiência, tentando, assim, solucionar entraves e alcançar os objetivos educacionais.

\section{REFERENCIAL TEÓRICO}

0 Ensino Fundamental tem como principal objetivo a formação básica do ser humano, e segundo o artigo 32 da Lei de Diretrizes e Bases da Educação Nacional (LDBEN) 9.394/96, ele deve garantir:

\footnotetext{
1- o desenvolvimento da capacidade de aprender, tendo como meios básicos - pleno domínio da leitura, da escrita e do cálculo; ll- a compreensão do ambiente natural e social, do sistema político, da tecnologia, das artes e dos valores em que se fundamenta a sociedade; III- o desenvolvimento da capacidade de aprendizagem, tendo em vista a aquisição de conhecimentos e habilidades e a formação de atitudes e valores; IV- o fortalecimento dos vínculos de familia, dos laços de solidariedade humana e de tolerância reciproca em que se assenta a vida social. (BRASIL, 1996).
}

Para que tais encaminhamentos sejam garantidos, faz-se necessária uma orientação às professoras que trabalham com as crianças, de modo que sua formação profissional as possibilite buscar soluções e manter tais metas em consonância com o trabalho realizado, função essa delegada aos processos de formação inicial e continuada de professoras.

Levando em consideração que a formação inicial de professores, na maioria das vezes, não possibilita aos estudantes que a cursam uma abrangência maior da área em que será desenvolvido seu trabalho, torna-se necessário avançar em vários aspectos. Nas políticas públicas direcionadas à educação, faz-se necessária a inserção de práticas para uma formação inicial e continuada que possibilite avanços sociais, cabendo a todos os responsáveis assumirem seu papel, de modo a proporcionar à escola, última instância das políticas educacionais, condições para tais avanços aos estudantes. 
Assim, de acordo com Gatti (2016, p. 37), “...] a educação pode ajudar no processo de criação de condições de maior equidade social pelo seu papel de disseminadora de conhecimento e de formadora de valores." Ainda, é afirmado na Resolução n. 2, de $1^{\circ}$ de julho de 2015, que define as Diretrizes Curriculares Nacionais para a formação inicial e continuada, que:

$\S 3^{\circ} \mathrm{A}$ formação docente inicial e continuada para a educação básica constitui processo dinâmico e complexo, direcionado à melhoria permanente da qualidade social da educação e à valorização profissional, devendo ser assumida em regime de colaboração pelos entes federados nos respectivos sistemas de ensino e desenvolvida pelas instituições de educação credenciadas. (BRASIL, 2015).

Observando tais necessidades, o tema da formação continuada é algo que necessita estar em constante discussão, pois a partir do desenvolvimento dessa temática, mudanças significativas e práticas podem ocorrer, resultando em melhorias na educação. De acordo com Rosa, Grosch e Lorenzini (2017, p. 1048),

[..] o processo de formação continuada não pode ser concebido como um acúmulo de informações, nem pode limitar-se à veiculação de novas teorias ou disseminação de novas políticas educacionais, mas como um processo de construção de conhecimento a partir de um coletivo pensante, onde a teoria seja a base das discussões numa metodologia que possibilite a reflexão sobre as experiências dos professores à luz de concepções teóricas, que não sejam descoladas dos conflitos enfrentados pelos professores em sala de aula.

Nas escolas municipais de Lages, a formação continuada acontece na Secretaria Municipal de Educação de Lages (SMEL), com base no artigo 33 da Lei complementar n. 353, de 3 de fevereiro de 2011, que dispõe sobre o plano de carreira e de remuneração do magistério no Município de Lages, SC, que trata sobre

A qualificação profissional, objetivando o aprimoramento permanente do ensino e a progressão na Carreira, será assegurada através de cursos de formação, aperfeiçoamento ou especialização, em instituiç̧̃es credenciadas de programas de aperfeiçoamento em serviço e de outras atividades de atualização profissional, observando os programas prioritários. $\$ 1^{\circ}$ A secretaria da educação do município de Lages ofertará um mínimo de 40 (quarenta) horas anuais de cursos de formação, programas de aperfeiçoamento e capacitação para todos os profissionais do magistério público municipal. (LAGES, 2011). 
A formação continuada para professoras alfabetizadoras será efetiva se possibilitar a elas a construção de bases sólidas que darão respaldo às necessidades dos estudantes, com "[...] ampliação da autonomia do professor e, ao mesmo tempo, uma apropriação, por ele, de conhecimentos, habilidades e valores fundamentais da cultura existente, bem como de conhecimentos necessários para assegurar aos alunos a apropriação ativa e criativa dessa cultura" (GROSCH, 2011, p. 148-149), nessa fase determinante para o sucesso escolar e ponto de partida para mudança de condições sociais. Alfabetizar com qualidade precisa fazer parte de projetos políticos para que haja mudanças nas condições apresentadas.

Assim, a formação continuada das professoras alfabetizadoras necessita ser um processo constante, flexível e relacionado às vivências cotidianas. Face a isso, é recomendável que ela não ocorra somente em momentos e/ou locais pré-determinados, a escola onde as professoras atuam é um ambiente que pode proporcionar diferentes oportunidades de aperfeiçoamento da prática pedagógica. É importante que essa formação possibilite a autonomia e a criticidade das professoras alfabetizadoras, para que elas desenvolvam essas condições também com os estudantes de suas turmas. Os ambientes de formação continuada podem propiciar que as professoras agreguem e socializem saberes, e, de acordo com Grosch (2018), quando as professoras atuam como protagonistas dos processos formativos e constroem soluções no coletivo, há maior entendimento com relação às políticas públicas, e os resultados poderão ser mais satisfatórios.

Nas práticas alfabetizadoras, é pertinente que educandos e educadoras sejam reconhecidos e solidários na construção dos conhecimentos por meio de processos de participação e aprendizagem. Da mesma forma, as políticas públicas necessitam ser colocadas em prática e a educação precisa ser prioridade, podendo desencadear mudanças em outras instâncias e proporcionar resultados efetivos em todos os níveis de desenvolvimento.

De acordo com Gatti (2008), nas últimas décadas houve uma onda crescente de cursos de formação continuada que resultaram de situações emergenciais na atual sociedade e da defasagem da formação inicial, gerando vários enfoques sobre entendimento da formação continuada. Para a autora,

Muitas das iniciativas públicas de formação continuada no setor educacional adquiriram, então, a feição de programas compensatórios e não propriamente de atualização e aprofundamento em avanços do conhecimento, sendo realizados com a finalidade de suprir aspectos da máformação anterior, alterando o propósito inicial dessa educação - posto nas discussões internacionais -, que seria o aprimoramento de profissionais nos avanços, renovações e inovações de suas áreas, dando sustentação à sua criatividade pessoal e à de grupos profissionais, em função dos rearranjos nas produções científicas, técnicas e culturais. (GATTI, 2008, p. 58). 
0 desempenho dos estudantes também está relacionado diretamente à capacidade que as professoras apresentam em relacionar todos os aspectos inerentes ao ato de educar, porém essa capacidade é em grande medida adquirida na sua formação como profissional da educação, e se, como já mencionado, a formação inicial na maioria das vezes é destituída desses aspectos, destaca-se a importância da formação continuada, a qual, de acordo com Dias e Souza (2017, p. 16), é "uma contínua formação vinculada às necessidades que se integram ao seu exercício profissional." De acordo com os Parâmetros Curriculares Nacionais (PCNs), que são diretrizes para orientar os educadores,

\footnotetext{
Além de uma formação inicial consistente, é preciso considerar um investimento educativo contínuo e sistemático para que o professor se desenvolva como profissional de educação. 0 conteúdo e a metodologia para essa formação precisam ser revistos para que haja possibilidade de melhoria do ensino. A formação não pode ser tratada como um acúmulo de cursos e técnicas, mas sim como um processo reflexivo e crítico sobre a prática educativa. Investir no desenvolvimento profissional dos professores é também intervir em suas reais condições de trabalho. (BRASIL, 1997, p. 25).
}

Quando inicia seu processo de alfabetização, a criança vê o mundo descortinarse à sua frente com novas e diferentes possibilidades, por isso é essencial que esse processo permita inúmeras oportunidades de aprendizagem. Para tanto, é importante que as professoras apresentem condições para auxiliar nesse processo. Verifica-se a imprescindibilidade de análises teóricas que auxiliem no processo de formação continuada das professoras, além de uma ampliação no campo de perspectivas para fundamentar e elencar posicionamentos necessários, de forma a contribuir para um processo de alfabetização mais sólido e significativo perante as diversas dificuldades encontradas no momento de alfabetizar, as quais são oriundas de aspectos da rotina escolar, bem como diferentes percepções e níveis de aprendizagem.

É importante afirmar que mudanças são necessárias, os professores são aqueles que proporcionarão aos estudantes acesso aos conhecimentos constituídos ao longo da história e mostrarão como relacioná-los à sua vida. Para tanto, é imprescindível que a carreira docente seja foco de políticas públicas que proporcionem mudanças efetivas, pois "A formação de professores não pode ser pensada a partir de ciências e seus diversos campos disciplinares, como adendo dessas áreas, mas sim, a partir da função social própria à escolarização [...]" (GATTI; GARCIA, 2011, p. 219-220). Concomitante a isso, o papel da escola como formadora de cidadãos necessita ser valorizado e visto como a possibilidade de ultrapassar as barreiras sociais e econômicas que visualizamos na constituição dos seres pelos quais a educação passou, mas não transformou. 
Na educação, teoria e prática precisam andar juntas, bem como se faz necessário que aspectos positivos de uma determinada teoria, quando alterada, sejam mantidos, de modo a perpetuar práticas com resultados positivos. Essa questão é visivelmente posta em ação, levando-se em consideração somente aspectos políticos, e as ações voltadas à educação sofrem constantemente com a falta de continuidade. Para Saviani (2013, p. 108), é essa a questão que pesa no fracasso de campanhas nacionais de alfabetização. Segundo ele, as campanhas "Fracassam porque são esporádicas, são descontínuas, não duram o tempo suficiente para se atingir o ponto de irreversibilidade." Ainda de acordo com o autor, "[...] a política educacional precisa levar em conta essa peculiaridade e formular metas não apenas a curto mas a médio e longo prazo [...]" (SAVIANI, 2013, p. 109).

No final da década de 1990 inúmeras ações surgiram, tanto no sentido de pesquisas acadêmicas quanto de políticas públicas, no intuito de buscar resolver as questões e os problemas da educação, principalmente com base na LDBEN 9.394/96. Exemplos desses programas direcionados à formação continuada de professoras que atuam nas etapas de alfabetização são o Programa de Formação de Professores Alfabetizadores (PROFA) 2002, o Pró-Letramento: Mobilização pela Qualidade da Educação 2005-2012, o Pacto Nacional na ldade Certa (PNAIC) 2012-2018, o Programa Mais Alfabetização 2018-2019 e, mais recentemente, a Política Nacional de Alfabetização (PNA) 2019.

Todos esses programas tiveram como intuito suprir as defasagens, constatadas mediante instrumentos avaliativos, do processo de alfabetização e letramento dos estudantes no início da escolarização e que influenciam na continuidade dos processos educacionais. 0 foco principal desses programas foi, principalmente, a formação continuada das professoras alfabetizadoras, e mesmo após o desenvolvimento destes, percebe-se a necessidade de maior ênfase e, principalmente, de constância e ininterrupção desses processos de desenvolvimento profissional.

Segundo dados do Indicador de Alfabetismo Funcional (INAF) de 2018, o nível de alfabetização está diretamente relacionado à duração de anos que uma pessoa permanece na escola. "A escolaridade mais uma vez se confirma como o principal fator explicativo da condição de Alfabetismo. Quanto mais alta a escolaridade, maior a proporção de pessoas nos níveis mais altos da escala lnaf [...]" (INSTITUTO PAULO MONTENEGRO, 2018), e mesmo com tantas críticas com relação à importância da instituição escolar, é a escola que possibilita um maior domínio do processo de alfabetização e a inserção do indivíduo nas práticas sociais.

Em consonância a isso, consideramos necessário que nas políticas e processos de formação continuada sejam criados espaços para discussão sobre essa relação docente, pois, conforme afirma Libâneo (2011, p. 85), "Trata-se da formação do profissional críticoreflexivo, na qual o professor é ajudado a compreender o seu próprio pensamento e a refletir de modo crítico sobre sua prática." Desse modo, para que os professores estimulem 
e organizem novos processos de aprendizagem junto aos estudantes, é fundamental que a formação continuada oportunize essas possibilidades aos professores.

Os processos formativos devem estar ancorados nas necessidades dos professores, sem o caráter de atualização, mas de constituição docente; esse processo de formação precisa fazer parte de um contexto maior no desenvolvimento da carreira. Esses momentos podem ser também de discussão sobre as práticas excludentes percebidas na educação, geradas por políticas públicas que não almejam uma independência intelectual da classe de professores e mesmo dos estudantes, que são formados também pela escola. 0 que precisamos é "um novo professor para uma nova escola, considerando que o contexto social em que a escola está inserida mudou e as perspectivas da educação demandam outra concepção de mundo, de sociedade, de homem e de aprendizagens." (GROSCH, 2011, p. 32).

Uma formação continuada condizente com a realidade relaciona os processos intelectuais à prática docente e proporciona a autoavaliação do trabalho realizado, dos métodos utilizados e dos resultados alcançados. Segundo Imbernón (2009), para que a formação permanente dos professores proporcione a mudança de conceito que se tem desse processo como maneira de renovar práticas, faz-se necessária também uma mudança maior na maneira como esses momentos são organizados, visualizando o docente como "um sujeito que tem capacidades de processamento da informação, análise e reflexão crítica, decisão racional, avaliação de processos e reformulação de projetos, tanto trabalhistas como sociais e educativos em seu contexto e com seus colegas." (IMBERNÓN, 2009, p. 48).

Há várias distorções nesses momentos de formação continuada, utilizando certos padrões ou encaminhamentos predeterminados como sendo regras, isso gera nos professores resistência a esse processo ou simplesmente uma reprodução desses encaminhamentos, que não ocasionam mudanças significativas. Assim, é imprescindível a instituição de "Uma formação que, partindo das complexas situações problemáticas educativas, auxilie a gerar alternativas de mudança no contexto onde se dá a educação." (IMBERNÓN, 2009, p. 53). Nesse sentido, na formação continuada é importante a oportunidade para os professores colocarem em prática, perante a realidade que vivenciam, saberes que auxiliem e possibilitem condições de transformação diante de suas dificuldades, pois um modelo pronto raramente abarcará todas as especificidades do processo educativo, bem como as diferentes realidades vivenciadas por diferentes professores.

Além disso, para que ocorram oportunidades de mudanças, será preciso não apenas a formação dos professores, mas também uma modificação de questões e nuances que envolvem o processo educacional, para, assim, possibilitar que estes coloquem em prática as alterações necessárias, embasados em uma formação que oportunize a eles planejarem e tomarem decisões, e não somente reproduzirem técnicas. Para isso, será imprescindivel sua 
participação no planejamento, na execução e na avaliação dessas ações, ocasionando na escola um processo de "ação-reflexão-ação" (IMBERNÓN, 2009, p. 54).

Ainda falta na educação a valorização daqueles que constituem seus saberes nas vivências diárias, que são um campo proficuo de verificação de teorias e relações entre diferentes saberes. Ressaltamos a necessidade dessa valorização também no espaço da escola, que pode ser o local mais adequado para que a troca de aprendizados gere resultados positivos. Para Candau (2011, p. 56), a “....] experiência dos professores, o dia a dia da escola é um locus de formação. Nesse cotidiano, ele aprende, desaprende, reestrutura o aprendizado, faz descobertas e, portanto, é nesse locus que muitas vezes ele vai aprimorando a sua formação."

Assim, os momentos coletivos de formação continuada na escola podem proporcionar que professores, de todas as etapas, mas, nesse caso, principalmente as professoras alfabetizadoras, encaminhem e pensem as intervenções necessárias no processo de alfabetização e letramento. André (2016, p. 20) defende a ideia de o professor assumir-se como pesquisador e, desse modo, tornar-se autônomo, realizando suas escolhas, assumindo resultados e sentindo-se "[...] mais bem preparado para exercer a sua atividade docente, a fim de propiciar uma aprendizagem significativa ao aluno."

0 conhecimento de diferentes propostas vem ao encontro da necessidade de mudanças práticas embasadas em concepções teóricas que defendam a função social da escola como lugar de proteção dos direitos humanos, já que vemos uma estreita relação entre desigualdade social e oportunidades educacionais. É urgente a necessidade da escola pública de formar cidadãos capazes de atingir patamares elevados de educação e capacidade de transformação da realidade social, a qual inicia já nos primeiros anos de escolarização. A falta de domínio da alfabetização, na sociedade atual, é uma das formas de exclusão, bem como o não acesso aos meios que favorecem e estimulam tal aprendizado. De acordo com Soares (2017, p. 24), o fracasso na alfabetização é um tema reincidente em nosso país, que “[...] não se explica, apenas, pela complexidade na natureza do processo; caso contrário, não se justificaria a predominante incidência desse fracasso nas crianças das classes populares."

As professoras alfabetizadoras, principalmente aquelas em início de carreira, em razão de uma formação inicial deficitária, na maioria das vezes, e com pouco tempo de prática necessitam, muitas vezes sozinhas, encontrar as possibilidades para atingir objetivos de cada fase da educação escolar. Para Soares (2017, p. 135), “[...] o que funciona na alfabetização seria o ensino integrado das múltiplas dimensões da aprendizagem da língua escrita."

Assim, é necessário oportunizar aos estudantes a aprendizagem das relações grafema-fonema, a alfabetização, bem como a utilização, a compreensão e o uso competente da leitura e escrita nas práticas sociais, o letramento. A alfabetização, na perspectiva do letramento, envolve um projeto educacional que, acima da simples decodificação de textos, 
priorize a apreensão e compreensão de significados, além da interpretação necessária para a transformação da realidade vivenciada.

Ainda de acordo com Soares (2017), o conceito de alfabetização diz respeito à aquisição do código da língua escrita, portanto ele é um processo que se encerra com essa obtenção, já o desenvolvimento da língua escrita e sua apropriação, o letramento, é um processo contínuo. Para a autora, a alfabetização "Trata-se de fenômeno de múltiplas facetas que fazem dele objeto de estudo de várias ciências" e "[...] o problema da alfabetização não está, apenas, nessa sua característica interdisciplinar. Além desta, é preciso considerar, ainda, os aspectos sociais e políticos que condicionam a aprendizagem, na escola, da leitura e da escrita." (SOARES, 2017, p. 24). Sendo assim,

\footnotetext{
[...] a formação do alfabetizador - que ainda não se tem feito sistematicamente no Brasil - tem uma grande especificidade, e exige uma preparação do professor que o leve a compreender todas as facetas (psicológica, psicolinguística, sociolinguística e linguística) e todos os condicionantes (sociais, culturais, politicos) do processo de alfabetização, que o leve a saber operacionalizar essas diversas facetas (sem desprezar seus condicionantes) em métodos e procedimentos de alfabetização, em elaboração e uso adequados de materiais didáticos, e, sobretudo, que o leve a assumir uma postura política diante das implicações ideológicas do significado e do papel atribuido à alfabetização. (SOARES, 2017, p. 28).
}

Para tanto, no processo de alfabetização e letramento é necessário considerar as especificidades de ambos; separá-los é um equívoco, porém eles também não podem ser confundidos. É necessário considerar as habilidades indispensáveis aos dois processos com suas muitas facetas. Para isso, a formação das professoras responsáveis por esse processo, as alfabetizadoras, faz-se necessária no sentido de oportunizar a elas a possibilidade de conhecer, identificar e valorizar as práticas de alfabetização e letramento com "[...] a necessidade de rever e reformular a formação dos professores das séries iniciais do ensino fundamental, de modo a torná-los capazes de enfrentar o grave e reiterado fracasso escolar na aprendizagem inicial da língua escrita nas escolas brasileiras." (SOARES, 2017, p. 47).

A alfabetização não é a única, mas uma das possíveis maneiras de um cidadão exercer seu papel na sociedade e desenvolver sua cidadania, que, para muitos, por vários motivos, é negada. Porém, "[...] só se estará contribuindo para a conquista da cidadania se, ao promover a alfabetização, propicia-se, sobretudo, condições de possibilidade de que os indivíduos se tornem conscientes de seu direito à leitura e à escrita, de seu direito a reivindicar o acesso à leitura e à escrita." (SOARES, 2017, p. 172). Desse modo, mais do que o acesso ao código da escrita, faz-se necessária a instituição de uma escola que promova condições não só da alfabetização, mas que juntos, a alfabetização e o letramento, 
oportunizem o exercício pleno da cidadania, "[...] o valor e a importância da alfabetização não são inerentes a ela, mas dependem da função e dos usos que the são atribuídos no contexto social." (SOARES, 2017, p. 173). Nessa tarefa, cabe àqueles que coordenam e praticam esse processo, as alfabetizadoras, os gestores e as secretarias de educação, assumirem a reflexão e a luta pela alfabetização e letramento, a fim de garantirem condições de acesso do direito à cidadania.

\section{METODOLOGIA}

A pesquisa é de abordagem qualitativa, utilizando como instrumento para a coleta dos dados o questionário e a entrevista semiestruturada. Após a aprovação do projeto pelo Comitê de Ética em Pesquisas (CEP) da UNIPLAC, com data de 2 de novembro de 2018, e sob o parecer 2.997440, iniciamos o trabalho de campo para, primeiramente, estabelecer um primeiro contato com as participantes. Para conseguir abranger a quantidade almejada de $30^{4}$ professoras para a primeira etapa da pesquisa, foi realizada uma visita ao Núcleo de Excelência em Educação Permanente I na SMEL, no mês de novembro de 2018, onde fui recebida por uma das formadoras, que são as responsáveis por organizar os processos formativos dos professores dos Anos Iniciais. Nesse momento tivemos acesso ao nome de 30 professoras efetivas, de $1^{\circ} \mathrm{e} / \mathrm{ou} 2^{\circ}$ ano e que atuam em diferentes Unidades Escolares da rede municipal de Lages, SC.

Em posse dessa listagem, foi possível iniciar a visita às escolas, explicar às gestoras sobre a pesquisa, e com a sua autorização, conversar com as professoras explicitando os objetivos da pesquisa, apresentando o Termo de Consentimento Livre e Esclarecido (TCLE) e verificando a disponibilidade de participação. Todas as professoras a quem tivemos acesso (somente em uma escola não fomos autorizados conversar com as professoras, sendo que gestora iria explicar a pesquisa elas, e estas também participaram) demonstraram interesse e disponibilidade (apenas uma afirmou que participaria do questionário, mas por motivos particulares não aceitaria participar da entrevista).

A pesquisa encaminha rumos a serem seguidos, entendimento de situações ou novos direcionamentos e, segundo Flick (2012, p. 161), ela orienta os percursos que são organizados nos modelos de decisão e ação e "[...] podem focar em uma, duas ou mais variáveis e no relacionamento entre elas [...]”, porém, como tem seus limites, não é recomendável criar expectativas em torno da resolução de adversidades do cotidiano, na verdade eles podem ser 4 Esse número foi estipulado como necessário para a identificação de 10 professoras que atendessem ao perfil da segunda
etapa da pesquisa, a entrevista semiestruturada. 
o ponto de partida para o desenvolvimento de uma pesquisa empírica. 0 que é possível é a condução em relação aos aspectos envolvidos nas questões a serem solucionadas. "Cada vez mais a ciência e a pesquisa - suas abordagens e resultados - informam a vida pública. Elas ajudam a constituir a base para as tomadas de decisão políticas e práticas." (FLICK, 2012, p. 16).

Essa etapa da pesquisa de levantamento padronizada, com visita às participantes, seguindo um roteiro pré-definido de perguntas fechadas e simples, junto a 30 professoras alfabetizadoras efetivas da rede municipal de educação de Lages com experiência em turmas de $1^{\circ}$ e/ou $2^{\circ}$ ano foi concluída, sendo que todos os questionários foram respondidos de forma escrita, poucos com a presença da pesquisadora. Foi escolhido esse modelo de pesquisa inicial para possibilitar a inclusão de uma quantidade maior de professoras alfabetizadoras, com o objetivo de comparar respostas e identificar 10 professoras para participarem da segunda etapa da pesquisa, a entrevista semiestruturada.

Desse modo, conseguimos traçar o perfil de uma amostra de professoras alfabetizadoras da rede municipal de Lages. Essa abordagem teve seu início no final do mês de novembro e início de dezembro do ano de 2018. 0 número de 30 professoras respondentes do questionário foi obtido envolvendo docentes de 15 Escolas Municipais de Educação Básica (EMEBs), incluindo professoras alfabetizadoras e professoras que também já foram alfabetizadoras, mas que no momento assumem outras funções na UE, uma que está trabalhando na SMEL e uma que está em função administrativa em um Centro de Educação Infantil Municipal (CEIM). A maioria das professoras optou por levar o instrumento de pesquisa e entregar em outro momento, mas com algumas professoras que estavam em hora-atividade ${ }^{5}$ foi possível o preenchimento com a presença da pesquisadora. Para a análise dos dados, as professoras foram nomeadas pela letra $P$ seguida de números de 1 a 30 sem nenhuma relação, mantendo, assim, sigilo e confidencialidade.

0 perfil das participantes da pesquisa é o seguinte: todas as professoras são do gênero feminino, três possuem graduação, 24 possuem especialização e três possuem a titulação de mestrado. A faixa etária é entre 26 e 55 anos de idade, 15 professoras têm até 10 anos de experiência como alfabetizadora e 15 possuem entre 12 e 25 anos de experiência. Com base nos critérios de inclusão e exclusão foram identificadas 10 professoras para participarem da entrevista semiestruturada.

Dando continuidade à pesquisa, foram agendadas as entrevistas que iniciaram no final do mês de janeiro de 2019 e encerraram no final do mês de maio do mesmo ano, de acordo com a disponibilidade de local, dia e horário das professoras. As entrevistas foram

\footnotetext{
A hora-atividade corresponde a 1/3 (um terço) da jornada de trabalho, é o período dedicado pelo docente para: - planejar, preparar e avaliar o trabalho didático; - colaborar com a administração da escola; - aperfeiçoar seu trabalho profissional; participar dos eventos da UE quando convocados (LAGES, 2011).
} 
gravadas com autorização das professoras na assinatura do TCLE, antes mesmo da aplicação dos questionários, e tiveram duração de tempo entre 18 e 46 minutos, seguindo o roteiro de perguntas. Após cada entrevista, já era realizada sua transcrição e arquivamento com as perguntas separadas para possível categorização e relação com os objetivos propostos.

A entrevista semiestruturada permite uma aproximação com os envolvidos nas questões a serem analisadas, pois possibilita um diálogo profícuo, capaz de gerar novas e diferentes possibilidades, além de oportunizar ao pesquisador uma estreita interação com o objeto de estudo, não sendo necessário seguir criteriosamente a sequência de perguntas, pois nesse tipo de pesquisa esse roteiro não delimita, mas direciona e permite novas indagações e uma maior profundidade, sendo que seu objetivo "[...] é obter as visões individuais dos entrevistados sobre um tema." (FLICK, 2012, p. 115).

A sequência das perguntas foi pensada de modo a permitir que as professoras alfabetizadoras explicitassem suas vivências e os objetivos da pesquisa fossem atingidos, sendo que, quando necessário e possível, novas inserções foram incluídas, pois "é apenas na situação da entrevista que você pode decidir quando e como sondar extensivamente" (FLICK, 2012, p. 116), complementando ou tentando entender da melhor forma o posicionamento da professora diante de tal questão.

Encerrada a etapa das entrevistas e transcrições, iniciamos o estudo do material coletado. Inicialmente lendo e relendo os textos, em uma nova leitura foram elencadas, com base nas perguntas, três categorias, sendo Alfabetização e letramento, Professoras alfabetizadoras e Formação continuada. Logo após, ocorreu juntamente com a leitura a relação de alguns aspectos decorrentes das falas das professoras, aspectos esses relacionados às categorias elencadas, sendo nomeados de subcategorias, ou seja, com relação à categoria Alfabetização e letramento, as professoras relataram em suas falas aspectos relacionados à concepção que têm desse processo, ponderando sobre necessidades dessa fase escolar, metodologias que utilizam, algumas características dos estudantes e a questão da interdisciplinaridade.

Na categoria Professoras alfabetizadoras, comentam sobre perfil, profissionalismo, práticas, autonomia e protagonismo. Na categoria Formação continuada, relatam a relação entre teoria e prática, entendimento, pontos fortes, fragilidades, PNAIC e políticas.

\section{RESULTADOS}

As professoras possuem saberes que necessitam ser valorizados, compartilhando ideias e vivências, na reflexão de suas ações relacionadas aos aspectos teóricos que 
perpassam toda a ação educativa. Para refletir sobre as ideias das professoras participantes da pesquisa optamos pela entrevista semiestruturada, pois nela, de acordo com Flick (2012), é possivel que o pesquisador aprofunde questões que estão sendo analisadas.

A iniciação escolar gera ansiedade não somente nos estudantes. As professoras alfabetizadoras também, a cada ano, são surpreendidas com uma carga de expectativa e preocupação. Expectativa por estar diante de novas possibilidades e desafios, e preocupação, pois sob sua responsabilidade há um grupo de crianças que necessita de orientação e encaminhamentos necessários ao seu desenvolvimento, e como sugere Silva (2007, p. 3),

Conduzir pedagogicamente uma criança para o mundo da escrita nos dias de hoje não é tarefa das mais fáceis e que, por isso mesmo, o condutor (professor) necessita de uma sintese permanente de conhecimentos provindos de diferentes áreas, além de uma sensibilidade - ou aconchego - muito grande quando das interações com as crianças nos passos da alfabetização.

Todas as professoras que participaram da pesquisa têm uma estreita relação com a alfabetização, mesmo aquelas com menos tempo de experiência, na maioria dos anos em que atuaram como professoras, estiveram em turmas de alfabetização em algum momento. Desse modo, identificam que os dois processos, a alfabetização e o letramento, têm suas especificidades, mas andam juntos, assim, mesmo nas turmas iniciais de alfabetização se faz necessária a inserção de práticas de letramento, que é entendido como o "[...] desenvolvimento de comportamentos e habilidades de uso competente da leitura e da escrita em práticas sociais [...]" (SOARES, 2017, p. 64), de modo que as crianças utilizem e relacionem os conhecimentos proporcionados na escola ao seu cotidiano. Soares $(2018$, p. 35$)$ defende que os dois processos devem atuar ao mesmo tempo, e

A aprendizagem inicial da língua escrita, embora entendida e tratada como fenômeno multifacetado, deve ser desenvolvida em sua inteireza, como um todo, porque essa é a natureza real dos atos de ler e de escrever, em que a complexa interação entre as práticas sociais da língua escrita e aquele que lê ou escreve pressupõe o exercício simultâneo de muitas e diferenciadas competências. É o que se tem denominado alfabetizar letrando.

Porém, a autora alerta para a necessidade do entendimento de cada um dos processos, pois é muito comum que esses conceitos se confundam. Afirma, então, que, "Embora a relação entre alfabetização e letramento seja inegável, além de necessária e até mesmo imperiosa, ela, ainda que focalize diferenças, acaba por diluir a especificidade de 
cada um dos dois fenômenos [...]" (SOARES, 2017, p. 35). Para as professoras participantes da pesquisa, alfabetizar na perspectiva do letramento é:

\begin{abstract}
[..] fazer com que eles los estudantes] entendam o processo, não o fim, eles têm que entender o processo ao qual eles estão inseridos, isso é letrar, é preparar eles para o todo [...] (P01).

Eu acho que as duas coisas caminham juntas, você não ensina só para criança decodificar o sinal, você ensina para que esse conteúdo seja significativo para a vida da criança e para que ela leve isso e entenda, então as duas coisas caminham juntas, são correlatas, mas têm as suas especificidades [...]. (P25) (informações verbais).
\end{abstract}

Identificamos que as professoras descrevem esses processos de acordo com os preceitos de Magda Soares, provavelmente isso se deve à formação continuada da rede municipal, que, durante a execução ${ }^{6}$ do PNAIC, tinha como principal teórica embasando esses processos a referida autora. Mais do que decifrar o código escrito, a leitura permite aos indivíduos uma participação ativa na sociedade, porém não basta a decifração. Relacionados a essa habilidade há a necessidade do entendimento e utilização social desse aprendizado, ou seja, o domínio das habilidades de leitura e escrita. Um dos desafios da escola brasileira, perante as dificuldades e diferenças encontradas, é possibilitar de maneira equilibrada e satisfatória esses aprendizados, onde a criança se alfabetiza em um contexto de letramento. Quando questionadas quanto à sua concepção sobre alfabetização e letramento, as professoras relatam:

\footnotetext{
Não só alfabetizar de forma mecânica, mas também trabalhar o dia a dia, o cotidiano, trazer significado para essa alfabetização para que eles possam usar na vida deles, não só para aprender aquele código e aquelas palavras, mas sim que é um todo, eu vejo assim que é um todo, é um processo que engloba muito mais do que só decodificar [...]. Fazer uma leitura do mundo que ele vive. (P21).

A alfabetização, ela simplesmente é mais você buscar a decodificação dos símbolos, é o ler e escrever. E o letramento eu acredito que ele vai mais para a função social que você vai destinar essa leitura e escrita, no que você vai usar, de que forma que vai usar, é a leitura de mundo é a leitura e a escrita na vida mesmo. (P30) (informações verbais).
} 
0 trabalho com as turmas de alfabetização exige saberes específicos das professoras, e muitas questões necessitam ser levadas em consideração para que estas desenvolvam um trabalho exitoso com essas turmas, pois algumas características, como o desenvolvimento infantil e a troca de ciclo da Educação Infantil para o Ensino Fundamental, são próprias dessa fase escolar. Desse modo, corroboramos com as participantes da pesquisa na ideia de que a escolha das professoras para atuarem nessas turmas precisa receber mais atenção, bem como o acompanhamento da prática dessas profissionais.

\begin{abstract}
[...] tanto na escola quanto na secretaria de educação, precisaria ter um critério para quem assume as turmas de alfabetização. Não é só ter ido bem na prova, mas de repente como era feito quando a gente trabalhava na escola particular, uma entrevista, ver a prática, são coisas que a gente vê que falta, porque depois vai apresentando problemas ao longo do ano. (P27) (informação verbal).
\end{abstract}

Em Lages, na rede municipal, essa determinação das turmas ocorre ou por escolha da professora efetiva ou seguindo a ordem de classificação do processo seletivo que não diferencia as turmas dos Anos Iniciais do Ensino Fundamental, ocasionando uma rotatividade de professores, impedindo a consolidação de projetos e posicionamentos da unidade escolar. Para Silva (2011, p. 45), "[...] o entre e sai ou troca constante de professores em uma instituição corrói, na base, qualquer proposta curricular." As professoras nos colocaram suas percepções sobre o assunto:

[...] tem muitos professores que você conhece, ano passado eu trabalhei com
quarto ano, esse ano pré-escola, outro ano esses já estão no segundo
ano, ai é claro que ele não se detém, porque além da prática tem que
ter um pouquinho de embasamento, então se o professor ficar dois/três
anos como professor do primeiro ano, vai estudar sobre conhecimentos
curriculares específicos para o primeiro ano, com a tua prática e mais os
conhecimentos gerais, leituras próprias para o primeiro ano, vai reforçar
o teu conhecimento e o teu trabalho. Porque se você vai para uma série
em um ano, e depois outra, você não se apropria, claro que algo fica, mas
não que você diga, eu vou trabalhar com esse aluno, então a gente tem
observado muito os professores nesse momento espećíico, eles trabalham
com várias séries, não têm uma série específica. (P14).

Ficando sempre com a mesma turma é bom, porque daí você vê aquilo que deu certo em um ano, o que precisa melhorar no outro. (P07) linformações verbais).

Temos como pressuposto que a capacidade de resolução de conflitos e a tomada de atitudes e soluções são adquiridas em grande parte com as experiências e os saberes 
vivenciados. Desse modo, a permanência em turmas de alfabetização, e também na mesma unidade escolar, pode gerar condições para que a professora construa uma base sólida de conhecimentos fundamentais no desenvolvimento da docência, relacionados às habilidades que se fazem necessárias às professoras alfabetizadoras, bem como o conhecimento dos estudantes, possibilitando partir daquilo que ele já domina a respeito dos conhecimentos curriculares.

Quando questionadas a respeito dos requisitos que julgam necessários para ser uma professora alfabetizadora, as professoras participantes da pesquisa nos colocaram:

\footnotetext{
Em primeiro lugar gostar do que faz, ser apaixonada pelo que faz [...] em segundo lugar comprometimento que você precisa ter com o trabalho, porque os resultados não aparecem de imediato [...] assim é preciso trabalho de paciência, é você ter certeza daquilo que você está fazendo, ter certeza do trabalho que está realizando, gostar e trabalhar todo dia. (P01).

Primeiro é ter o conhecimento do que é alfabetizar. Eu acho que a professora tem que ter claro qual a intenção que ela tem de chegar na sala de aula para que a criança naquele momento se alfabetize, mas ela também tem que ter claro que essa criança já vem com um percurso formativo lá da pré-escola e pela formação que ela tem [...]. Tem que ter claro o que é alfabetizar, de que forma você vai fazer, e isso a gente consegue lendo, com a experiência, com o dia a dia da sala de aula. (P25) linformações verbais).
}

Percebemos, pelas falas mencionadas, o quão exigente é o trabalho das professoras e que elas têm clareza de que não basta o domínio dos conteúdos ou somente as estratégias selecionadas para alfabetizar. Compromisso, paciência, conhecimento, articulação e observação são alguns dos requisitos que as professoras necessitam desenvolver no exercício da profissão. Silva (2007, p. 3) também nos coloca que "[...] as melhores alfabetizadoras são mulheres que encarnam valores como tolerância, paciência e esperança, movendo para frente o ensino do código, com todas as minúcias que isso exige, e antevendo a mágica ou o milagre de ver os seus alunos produzindo sentido aos textos."

Embora a educação não seja a única possibilidade de resolução das mazelas da sociedade, ela é uma das grandes responsáveis pelas oportunidades de mudanças, mesmo com o desenvolvimento acelerado e constante das tecnologias. Mudanças que necessitam do domínio da linguagem escrita. Assim, as professoras alfabetizadoras que têm como responsabilidade a concretização desse processo necessitam assumir posicionamentos que permitam tais avanços, além de um compromisso para com os estudantes.

Ainda, de acordo com Imbernón (2010, p. 55), atualmente "[...] temos certeza de que a educação só mudará se os professores mudarem, mas os contextos em que esses interagem também deverão fazê-lo." Assim, faz-se necessária uma formação de professores 
que oportunize uma mudança de ação, o contexto educacional necessita permitir-lhes agir, e a formação continuada "requer dar a palavra aos protagonistas da ação, responsabilizá-los por sua própria formação e desenvolvimento dentro da instituição educacional na realização de projetos de mudança." (IMBERNÓN, 2010, p. 55).

De acordo com Gatti (2011, p. 185), várias possibilidades se abrem no campo da formação de professores, em alguns momentos essa formação se restringe aos cursos após a graduação, em outros momentos é um conceito mais amplo, "[...] compreendendo qualquer tipo de atividade que venha a contribuir para o desempenho profissional [...]"

Quando questionadas sobre o que entendem por formação continuada, as professoras participantes da pesquisa relatam:

É estar sempre buscando melhorar aquilo que você já sabe, aprimorar aquilo que não deu certo, buscar o porquê que não deu certo, é importante por isso. É a mesma da prática, assim de sempre estar no mesmo ano, a formação também auxilia nesse sentido. (P07).

A formação continuada é auxiliar o professor nesse processo, é trazer informações, inovações, contribuir também para socializar a prática de cada um, ter outras perspectivas, aprender realmente, trocar experiências. (P21).

Formação continuada para mim é um processo contínuo de aprimoramento do trabalho do professor, que ele vai aprimorar a prática junto com a teoria [...] é um momento de estudo, de dedicação do professor com o processo [...]. (P30) (informações verbais).

A professora P25 ainda ressalta a necessidade de as professoras encararem esse processo como um crescimento interno, independentemente das cobranças e dos cursos oferecidos.

\footnotetext{
[...] a leitura que você tem, que você faz, o que você busca também te ajuda mais, mas tem outros meios também, porque às vezes a troca com o outro, mais experiente que você, também é importante, a troca com pessoas e com formadores que são especialistas nisso também é importante, a tua leitura, então não só o curso da secretaria, mas outros meios também. A continuação tem que estar em você, muitas vezes o que acontece? $A$ formação continuada é oferecida pela secretaria, mas você é obrigada a ir lá, eu acho que essa continuidade tem que estar no teu entendimento, é uma continuidade que eles te ensinam lá, te orientam lá, mas essa continuidade você vai dar na tua sala de aula, nos teus estudos pessoais, na troca com ○ outro, então tem que vir de você essa continuidade, isso que eu penso. (P25) (informação verball.
} 
Percebemos que as professoras têm clareza de que a formação continuada é essencial na prática pedagógica, que se trata de um processo contínuo e de aperfeiçoamento da profissão. Porém, defendem que essa formação tenha estreita relação com a prática pedagógica, que seja colocada em prática, pois "a formação do professor só tem sentido quando analisa o fazer docente, permitindo um constante movimento entre teoria e prática." (SILVA; SANTOS, 2013, p. 286). E com relação ao processo de formação continuada ofertado pela Secretaria Municipal de Educação de Lages, ressaltaram:

\footnotetext{
Eu acho assim, que caminham juntos tanto a teoria como a prática, mas um não pode ser dissociado do outro, sabe você tem que ter essa clareza que nem sempre você vai atingir todos do mesmo grau e nem sempre os seus objetivos, não pode ter um objetivo único para todos. (P15).
}

Às vezes muita teoria e pouca prática, eu acho que poderia ter mais a prática, eles poderiam mostrar melhor como fazer, porque às vezes você tem essa carência, tem crianças que você não consegue, não consegue avançar, de repente alguém conseguiu de uma forma que eu desconheço, que eu ainda não me detive naquilo, acho que é importante ter a teoria óbvio, mas eu acho que a prática também seria muito interessante. (P23) (informações verbais).

Fica visivel a necessidade que há em perceber as situações e teorias trabalhadas nos cursos de formação continuada na prática cotidiana da sala de aula. Corroboramos com Imbernón (2015) quando defende que é necessária uma "formação a partir de dentro", ou seja, de acordo com as necessidades da prática e preferencialmente no espaço escolar, aliando "A união da formação a um projeto de trabalho central. Uma formação no local de trabalho, onde se deem as situaçães-problema, o que significa uma formação a partir de dentro." (IMBERNÓN, 2015 , p. 81), levando em conta aspectos teóricos, mas também necessidades pontuais da rotina escolar, algo que necessita ser individualizado, pois cada escola e/ou comunidade tem suas características e peculiaridades.

As professoras alfabetizadoras participantes da pesquisa enaltecem a formação continuada em vários aspectos, principalmente quando esta possibilita o compartilhar de experiências, o aprimoramento da prática pedagógica, a valorização dos saberes desenvolvidos e, principalmente, quando essa formação as auxilia nas questões inerentes às dificuldades de aprendizagem apresentadas pelos estudantes. Quando indagadas sobre as características positivas da formação continuada, as professoras nos dizem que:

[...] na formação a gente recorda, a gente relembra e vai melhorando naquilo que é possivel [...]. Com certeza, a gente vem mais com aquela certeza de que vai dar certo, porque de início sempre a gente fica em dúvida, não sabe até que ponto, e não tem, não existe uma receita pronta assim também, 
então através dessa troca de experiências que a gente tem também, vê que não é só com a gente que acontece, que é um processo mesmo, que a alfabetização é, para uns é difícil, para outros nem tanto, então depende de cada aluno também, de cada realidade deles, e é através dessa troca de experiências que ajuda bastante, a gente vem mais motivada. (P07).

[..] eu acho que às vezes a troca ali com o outro é importante, assim como a troca entre os alunos é importante, a troca entre nós professores é importante [...] Acho que a troca de experiências entre professores nos cursos é muito gratificante [...] a troca com as colegas se torna mais rica do que o material em si [...] (P15) (informaç̃̃es verbais).

Percebemos pelos relatos que as professoras valorizam esse processo, porém quando está direcionado à rotina diária da sala de aula, parecendo ser esse um aspecto mobilizador para a inserção de qualquer mudança e/ou novos direcionamentos. Ou seja, partindo da prática e das necessidades cotidianas para buscar e relacionar aspectos teóricos e, desse modo, possibilitar às professoras a identificação da necessidade de estudo e novos conhecimentos.

Outro ponto que as professoras alfabetizadoras defendem como essencial para fortalecer os processos formativos é a permanência das professoras nessa fase da educação escolar, de modo a manter uma formação que não necessita anualmente iniciar do zero e fortalece o grupo de alfabetizadoras da rede municipal, além da edificação de saberes necessários que são desenvolvidos a partir da experiência, mediante conquista e promoção dos saberes acumulados com relação à realidade vivenciada. "Isto implica não só um conhecimento da experiência de cada professor, de sua memória e de seu saber prático, seu ciclo de vida profissional, mas uma referência com a forma de pensamento e ações próprias do cotidiano e do contexto social em que está inserido." (GROSCH, 2018, p. 80). Sobre o processo de formação, as professoras relataram:

Eu sempre uso dizer que quando eu comecei na rede, nós tínhamos um grupo de alfabetizadores, você ia na formação e você encontrava sempre as mesmas pessoas, que eram as professoras alfabetizadoras, e nós tínhamos na época uma supervisão mais de perto do pessoal da secretaria, nós tínhamos a formação na secretaria de educação e depois essa formadora passava nas nossas salas de aula para acompanhar como é que estava, como é que o trabalho ia acontecendo em sala de aula. (P06).

Assim, o que a gente observa na formação é que tem uma rotatividade muito grande de pessoas, antes nós tínhamos um grupo de alfabetizadores, que as pessoas que se identificavam ficavam ali, não tinha muita mudança de professor, os alfabetizadores eram alfabetizadores e tinha essa troca. (P25) (informações verbais). 
Identificamos que as professoras têm carências que necessitam ser levadas em conta, estas relacionadas às dificuldades que surgem no exercício da docência, sendo este um dos possíveis caminhos para o ensaio de novas práticas nos processos de formação continuada de professoras. Como relata André (2013, p. 48), “0 levantamento e análise das necessidades formativas junto aos docentes [...] é um aspecto que ainda merece séria consideração por parte dos órgãos executores das políticas." Conforme relatado, as professoras ressaltam a necessidade das especificidades com relação à alfabetização que se fazem urgentes nos processos formativos das professoras.

É porque, assim, o primeiro ano e o segundo acabam sendo, e é a base do aprendizado escolar, então se você não investir ali com os alunos e com os professores, as crianças vão com essa defasagem, se o professor já é defasado como que vai ser a aprendizagem lá na sala de aula? Então esse investimento, eu acho que é importante ter lá [...] (P25) (informação verbal).

As professoras participantes da pesquisa demonstram certa apreensão a respeito das mudanças ocorridas nas políticas de formação continuada de alfabetizadoras. De acordo com Rosa, Grosch e Lorenzini (2017, p. 1048), os avanços que se pretende alcançar com a mudança de políticas públicas "[...] se não forem discutidos com o coletivo de professores, e se estes profissionais não se constituírem como sujeitos do processo, podem provocar insegurança, insatisfação, frustração, e ainda resistências na materialização dessas políticas." Na fala das professoras:

\footnotetext{
[..] agora com a BNCC, me parece que a gente tem que trabalhar novamente por habilidades e nem todas as habilidades se casam, então eu senti que a BNCC, talvez até porque a gente também não tenha muito conhecimento e ainda está iniciando, engatinhando nesse processo, eu acho que houve, digamos assim que ficou um vácuo, entre o PNAlC e agora a BNCC, uma quebra muito grande e muitas diferenças, uma mudança muito radical [..] eu acho que nunca senti tanto essa quebra na rede municipal, por mais modismos na educação que tenham existido, acho que agora ficou uma coisa muito complicada, não sei se são as cobranças em cima de muito papel, sabe a parte muito burocrática, muita cobrança de plano, de planejamento em cima da BNCC, que é um documento que é novo para você, então primeiro você teria que conhecer muito bem, para depois fazer, então a gente sofre muito, estamos sofrendo muito em fazer os planos de aula. (P23) (informação verball.
}

Para as professoras, não está ocorrendo uma relação entre o PNAIC, que foi a política anterior para alfabetizadoras, e os novos encaminhamentos relacionados à BNCC. Esse fator se torna visível sempre quando há trocas de governo; a falta de continuidade 
nas políticas, como já citado por Saviani (2013), é um dos grandes problemas educacionais, impedindo sua materialidade. Segundo ele, “Com esse grau de descontinuidade, não há como fazer frente às questões especificamente educacionais", e as políticas públicas precisariam “[... ser implementadas e avaliadas no seu processo e nos seus resultados, sendo corrigidas, quando for o caso, mas que tenham sequência, e que permitam criar situações irreversíveis de tal modo que as mudanças de governo não desmantelem aquilo que está sendo construído." (SAVIANI, 2013, p. 109). Para as professoras:

\begin{abstract}
[...] agora percebemos que as politicas estão mudando, e a gente fica um pouco perdido. [...] a BNCC ela não traz assim, como que eu vou te falar, ela não traz assim como você vai alfabetizar essa criança, que foi o que o PNAIC te deu, mas percebo que a segmentação dos conteúdos, tudo dificulta para trabalhar na perspectiva do PNAIC, estamos achando dificuldade de englobar - PNAIC na BASE [...] porque o documento está pronto, digamos assim, você tem ali várias habilidades que você tem que trabalhar, só que dentro de cada habilidade daquela a gente sente um pouco de dificuldade de trabalhar da forma como era feito no PNAIC. (P21) (informação verbal).
\end{abstract}

De acordo com Rosa, Grosch e Lorenzini (2017, p. 1054), há a necessidade de inserção dos professores na decisão e implementação de políticas educacionais, pois estas

\footnotetext{
[...] não podem ser apenas um projeto de governo, mas sim um projeto de Estado, no qual todos os professores efetivos da rede de ensino sintamse sujeitos do processo e possam defender e dar continuidade às ações engendradas por uma equipe, que se sabe transitória pelo processo democrático de mudança de governo.
}

A formação continuada possibilita às professoras avaliarem e repensarem sua prática, retomarem ações que ao longo do tempo foram deixadas de lado, porém que ainda são úteis e favoráveis à aprendizagem. Favorece o compartilhar de experiências entre professoras que vivenciam realidades parecidas ou não, e colabora com a busca de soluções, pois a reflexão em conjunto oportuniza um campo maior de possibilidades. Assim, esses processos necessitam ser pensados a partir destas, com base em suas necessidades, mas, e principalmente, com sua inserção na decisão dos caminhos a serem percorridos.

Ao longo das análises podemos perceber, com base no diálogo com as professoras, que elas valorizam e reconhecem o papel fundamental da formação continuada, porém dão menor valor para ações que não lhes parecem ter significado concreto e imediato na aprendizagem efetiva dos estudantes e na resolução das dificuldades que se fazem presentes no cotidiano escolar, desconsiderando as questões subjetivas que exigem discussões teóricas mais aprofundadas. Percebem que podem ser protagonistas 
e valorizadas nesses processos de formação, respeitam o trabalho que é realizado pelas equipes formativas, porém têm necessidades ainda pouco reconhecidas.

\section{CONCLUSÕES}

A pesquisa em questão possibilitou-nos evidenciar a necessidade da formação continuada como processo coletivo e participativo. Coletivo na medida em que considera as diferenças perceptíveis na educação e que contribui nas práticas educativas. Participativo na medida em que valoriza essas mesmas práticas e possibilita aos professores se verem como sujeitos desses processos de formação. Constantemente há a criação de diferentes propostas no campo da formação de professores que, na maioria das vezes, desconsideram os percursos formativos já percorridos e promovem, como foi possível verificar na pesquisa, uma instabilidade no desenvolvimento das práticas pedagógicas. Necessitamos, sim, de políticas de Estado, e não só de governo que primem pela valorização da carreira do magistério e políticas de formação continuada que possibilitem a consolidação de uma base teórica das práticas pedagógicas no exercício da docência.

Os dados nos revelaram a necessidade de valorização dos saberes das professoras e a consideração sobre suas dificuldades no desenvolvimento de sua profissão, sendo esse o ponto de partida para qualquer nova mediação nos processos formativos, bem como a estreita relação entre a equipe de formadoras da SMEL, com aprofundamento teórico e também vivência de práticas, além da inserção no espaço escolar, de modo que esses processos de formação considerem os diferentes estágios de desenvolvimento da carreira das professoras com relação às diferentes necessidades das escolas da rede municipal de educação de Lages.

Reforçamos a necessidade da formação continuada como construção de conhecimentos e não somente de cumprimento de determinado número de horas para certificação e aumento salarial, erro comum em alguns processos formativos, que não valorizam os avanços adquiridos anteriormente e práticas que causaram impactos positivos, desestabilizando e desconfigurando esses processos, com enfoque em questões que não fortalecem a carreira docente.

Proporcionar condições para que todos se alfabetizem é um grande desafio, assim enfatizamos o cuidado e o auxílio que merecem e necessitam essas turmas e professoras, e nesse ponto a formação continuada e as pessoas que a coordenam e organizam desempenham um papel primordial, no sentido de reconhecer esse desafio e 
proporcionar condições de enfrentamento a ele, auxiliando as professoras alfabetizadoras e permitindo condições para que objetivos sejam alcançados.

Em consonância aos estudos realizados, as professoras confirmam a importância de a formação continuada levar em consideração as práticas e exigências educacionais e primar pela valorização da função social da escola. Exaltam, também, a premência de práticas alfabetizadoras que promovam com os estudantes possibilidades de avanços no conhecimento e transformação da realidade social em que vivem, mas reconhecem que ainda thes falta subsídios para tratar das questões de aprendizagem dos estudantes, e muito do que realizam com relação à alfabetização e ao letramento parte da experimentação pedagógica na prática do cotidiano escolar.

Assim, uma formação continuada que seja aquela proporcionada pelas políticas públicas, muito mais que direcionamentos e orientações, pode pautar-se na participação coletiva e individual, de modo a proporcionar a todas as alfabetizadoras as condições necessárias e possíveis para seu crescimento profissional e, consequentemente, dos índices educacionais referentes à alfabetização e ao letramento, na relação entre o que é fundamental e o que é possível perante realidades e oportunidades vivenciadas e oferecidas, deixando de lado expectativas individuais para o compromisso de benefícios comuns.

\section{REFERÊNCIAS}

ANDRÉ, M. Formar o professor pesquisador para um novo desenvolvimento profissional. In: ANDRÉ, M. (org.). Práticas inovadoras na formação de professores. Campinas: Papirus, 2016. p. 17-34.

ANDRÉ, M. Políticas de apoio aos docentes em estados e municípios brasileiros: dilemas na formação de professores. Educar em Revista, Curitiba, n. 50, p. 35-49, 2013.

BRASIL. Lei n. 9.394, de 20 de dezembro de 1996. Estabelece as diretrizes e bases da Educação Nacional. Diário Oficial da União, Brasília, DF, 1996.

BRASIL. Ministério da Educação. Parâmetros Curriculares Nacionais: Introdução aos parâmetros curriculares nacionais. Brasília, DF: Secretaria da Educação Fundamental, 1997.

BRASIL. Ministério da Educação. Plano Nacional de Educação - PNE. Brasilia, DF: INEP, 2001.

BRASIL. Ministério da Educação. Resolução n. 2, de $1^{\circ}$ de julho de 2015. Define as Diretrizes Curriculares Nacionais para a formação inicial em nível superior (cursos de licenciatura, cursos de formação pedagógica para graduados e cursos de segunda licenciatura) e para a formação continuada. Brasilia, DF: MEC, 2015. Disponivel em http://portal.mec.gov.br/docman/agosto-2017-pdf/70431-rescne-cp-002-03072015-pdf/file. Acesso em: 30 mar. 2018. 
CANDAU, V. M. Formação continuada de professores: tendências atuais. In: CANDAU, V. M. (org.). Magistério: construção cotidiana. Petrópolis: Vozes, 2011. p. 51-68.

DIAS, M. da S.; SOUZA, N. M. M. de. Contribuições para Compreender a Formação na Licenciatura e na Docência. Educação em Revista, Belo Horizonte, v. 33, p. 1-24, 2017.

FLICK, U. Introdução à Metodologia de Pesquisa: um guia para iniciantes. Porto Alegre: Penso, 2012.

GATTI, B. A. Análise das políticas públicas para formação continuada no Brasil, na última década. Revista Brasileira de Educação, Rio de Janeiro, v. 13, n. 37, p. 57 -70, 2008.

GATTI, B. A. GARCIA, W. E. (org.). Bernardete A. Gatti: educadora e pesquisadora. Belo Horizonte: Autêntica Editora, 2011.

GATTI, B. A. Questões: professores, escolas e contemporaneidade. In: ANDRÉ, M. (org.). Práticas inovadoras na formação de professores. Campinas, SP: Papirus, 2016. p. 35-48.

GROSCH, M. S. A formação continuada de professores na rede municipal de ensino de Blumenau: a escola de formação permanente Paulo Freire - EFPPF (1997-2004). 2011. Tese (Educação) - Programa de Pós-Graduação em educação, Universidade Federal de Santa Catarina, Florianópolis, 2011.

GROSCH, M. S. Ação humana, atividade docente e formação continuada de professores: perspectiva a partir do pensamento de Hannah Arendt. Revista Tempos e Espaços em Educação, São Cristóvão, Sergipe, v. 11, n. 25, p. 71-82, 2018.

IMBERNÓN, F. Formação permanente do professorado: novas tendências. São Paulo: Cortez, 2009.

IMBERNÓN, F. Formação continuada de professores. Porto Alegre: Artmed, 2010.

IMBERNÓN, F. Novos desafios da docência no século XXI: a necessidade de uma nova formação docente. In: GATTI, B. A. et al. (org.). Por uma revolução no campo de formação de professores. São Paulo: Unesp, 2015. p. 75-82.

INSTITUTO PAULO MONTENEGRO. Inaf Brasil 2018: resultados preliminares. [S. I]: Instituto Paulo Montenegro, 2018. Disponível em: https://acaoeducativa.org.br/wp-content/uploads/2018/08/Inaf2018_ Relat\%C3\%B3rio-Resultados-Preliminares_v08Ago2018.pdf. Acesso em: 22 nov. 2018.

LAGES. Lei n. 353, de 03 de fevereiro de 2011. Dispõe sobre o plano de carreira e de remuneração do magistério do município de Lages - SC. Lages, SC, fev. 2011.

LIBÂNEO, J. C. Adeus Professor, Adeus Professora? Novas exigências educacionais e profissão docente. 13. ed. São Paulo: Cortez, 2011. 
ROSA, G. A. da; GROSCH, M. S.; LORENZINI, V. P. Reflexões sobre educação na contemporaneidade: certezas, (in) certezas e desafios. Revista lbero-Americana de Estudos em Educação, Araraquara, v. 12, n. 2, p. 1037-1055, 2017.

SAVIANI, D. Pedagogia Histórico-Crítica. 11. ed. Campinas, SP: Autores Associados, 2013.

SILVA, A. C. da; SANTOS, S. M. dos. Avaliação da formação continuada no Estado do Rio de Janeiro: um estudo de caso. Ensaio: Avaliação e Políticas Públicas em Educação, Rio de Janeiro, v. 21, n. 79, p. 269-298, 2013.

SILVA, E. T. da. Os (des) caminhos da escola: traumatismos educacionais. 8. ed. São Paulo: Cortez, 2011.

SILVA, E. T. da. Prefácio. In: SILVA, E. T. da. Alfabetização no Brasil: questões e provocações da atualidade. Campinas, SP: Autores Associados, 2007. p. 1-5.

SOARES, M. B. Alfabetização e letramento. 7. ed. São Paulo: Contexto, 2017.

SOARES, M. B. Alfabetização: a questão dos métodos. São Paulo: Contexto, 2018.

Endereço para correspondência: rua Manaus, 707, Santa Helena, Lages, Santa Catarina, Brasil; letiarruda2908@gmail.com

Roteiro, Joaçaba, U. 45, p. 1-28, jan./dez. 2020 | e24025 |E-ISSN 2177-6059 
